\title{
Consequences of bleeding after thyroid surgery - analysis of 7805 operations performed in a single center
}

\author{
Beata Wojtczak, Michał Aporowicz, Krzysztof Kaliszewski, Marek Bolanowski
}

Department and Clinic of General, Gastroenterological and Endocrine Surgery, Wroclaw Medical University, Wroclaw, Poland

Submitted: 21 September 2015

Accepted: 8 November 2015

Arch Med Sci 2018; 14, 2: 329-335

DOI: 10.5114 /aoms.2016.63004

Copyright $\odot 2016$ Termedia \& Banach

\section{Abstract}

Introduction: Surgical treatment of thyroid gland diseases is associated with the possibility of severe complications. The most dangerous of them is bleeding. Current studies focus on its risk factors, rather than reoperation-related consequences.

Material and methods: We analyzed 7805 thyroid operations performed from 1996 to 2014 in the Clinic of General, Gastroenterological and Endocrine Surgery of Wroclaw Medical University. Typical risk factors, symptoms and consequences of bleeding were analyzed.

Results: Among operated patients $88.2 \%$ were female and $11.8 \%$ male. Bleeding occurred in $84(1.08 \%)$ patients. Sex $(p=0.006)$, preoperative thyroid pathology $(p=0.03)$, and type of operation $(p<0.001)$ are significant risk factors for bleeding, while retrosternal goiter and surgeon's experience are not. Risk of bleeding is highest in the case of male sex, toxic goiter and total resection of the thyroid gland. Most reoperations took place within $6 \mathrm{~h}$. In $88.8 \%$ of cases of this kind of complication the surgeon indicated the exact source of bleeding; most commonly it was the neck muscles, skin and subcutaneous tissue, or the thyroid stump. Three patients required a second reoperation, 24 suffered further complications, and 8 required transfer to the Intensive Care Unit (ICU). Cardiac arrest occurred in 3 patients and 2 suffered bilateral vocal cord palsy.

Conclusions: Bleeding after thyroid operations is a direct life threat that requires immediate intervention. As a result death may occur, half of patients suffer other complications and some require intensive care. The risk is highest in the case of male sex, toxic goiter and total resection of the thyroid gland. Each patient after thyroid surgery needs to be closely observed. An operating theatre and ICU should be available at all times.

Key words: thyroidectomy, outcomes, complications, bleeding, reoperation.

\section{Introduction}

Surgical treatment of thyroid gland diseases is associated with the possibility of severe postoperative complications, such as recurrent laryngeal nerve palsy, superior laryngeal nerve injury, parathyroid insufficiency and bleeding. Both vocal cord palsy and hypoparathyroidism can undoubtedly decrease the patient's quality of life; bleeding, however, is genuinely life-threatening and requires immediate surgical intervention. Bleeding after a thyroidectomy is in itself a severe complication, and reoperation due to bleeding may entail further complications, including death.

\author{
Corresponding author: \\ Beata Wojtczak MD, PhD \\ Department and Clinic \\ of General, \\ Gastroenterological \\ and Endocrine Surgery \\ Wroclaw Medical University \\ 66 M. Curie-Sklodowskiej St \\ 50-369 Wroclaw, Poland \\ Phone: +48717842162 \\ Fax: +48 713270929 \\ E-mail: beatawojtczak@wp.pl
}


According to the available literature, the incidence of bleeding after thyroid gland surgery varies from $0 \%$ to $4.2 \%$ [1-9]. The rate is related to a given center's experience, as shown in a Dutch study in which the frequency of bleeding ranged from $1.9 \%$ to $14.3 \%$ in different hospitals [10]. However, in highly experienced departments the rate usually does not exceed $1 \%[11,12]$.

The majority of studies on bleeding after thyroid operations focus on finding and analyzing risk factors. The indications for the primary procedure (the type of thyroid disease), the scope of the operation, the patient's age and sex, as well as the individual surgeon's experience are analyzed in such studies. Understanding risk factors is essential, as it allows surgeons to decrease the incidence of this dangerous complication. On the other hand, there are very few studies concerning the consequences of the bleeding itself and the associated reoperation. The authors of this paper therefore decided to focus on these subjects, and whether bleeding after thyroidectomy should really be feared.

Table I. Bleeding after thyroid operations in years 1996-2014

\begin{tabular}{|c|c|c|}
\hline Year & Thyroid operations & $\begin{array}{c}\text { Number of bleeding } \\
\text { cases, } n(\%)\end{array}$ \\
\hline 1996 & 261 & - \\
\hline 1997 & 183 & $4(2.19)$ \\
\hline 1998 & 213 & $1(0.47)$ \\
\hline 1999 & 430 & $4(0.93)$ \\
\hline 2000 & 333 & $2(0.60)$ \\
\hline 2001 & 423 & $3(0.71)$ \\
\hline 2002 & 469 & $8(1.71)$ \\
\hline 2003 & 395 & $3(0.76)$ \\
\hline 2004 & 452 & $2(0.44)$ \\
\hline 2005 & 490 & $5(1.02)$ \\
\hline 2006 & 382 & $6(1.57)$ \\
\hline 2007 & 399 & $2(0.50)$ \\
\hline 2008 & 447 & $9(2.01)$ \\
\hline 2009 & 380 & $2(0.53)$ \\
\hline 2010 & 410 & $3(0.73)$ \\
\hline 2011 & 496 & $6(1.21)$ \\
\hline 2012 & 539 & $4(0.74)$ \\
\hline 2013 & 555 & $15(2.70)$ \\
\hline 2014 & 548 & $5(0.91)$ \\
\hline Total & 7805 & $84(1.08)$ \\
\hline
\end{tabular}

\section{Material and methods}

We retrospectively analyzed 7805 thyroid operations due to various pathologies, performed from January 1996 to December 2014 - a total of 19 years' experience. All the patients were treated in the Clinic of General, Gastroenterological and Endocrine Surgery at Wroclaw Medical University (Wroclaw, Poland), which is a highly specialized surgical center that has focused on thyroidectomy for decades. The operations were performed by highly experienced surgeons as well as surgical residents.

In this 19-year period we observed a gradual shift in the scope of the procedures, especially in patients undergoing surgery for multinodular goiter. Two decades ago most of these patients underwent subtotal bilateral thyroidectomy, but now most of them undergo total resection of the thyroid gland. In addition, in 2012 neuromonitoring of the recurrent laryngeal nerve was introduced in our clinic.

In the clinic it is a standard protocol to leave a suction drain after a thyroidectomy, which is removed 2 days later. Every patient that has had neck surgery is closely observed and monitored for at least $2 \mathrm{~h}$, then most of them are transferred to the general surgical ward, where a nurse checks the patient's condition every hour. In cases of additional risk, the monitoring period is prolonged to $12 \mathrm{~h}$. The standard hospitalization time after thyroid surgery is $48 \mathrm{~h}$.

The patients' data - age, sex, pre- and postoperative diagnosis, type of procedure, complications, performing surgeon - were stored in the clinical database. Typical risk factors were analyzed, as well as time from skin closure to reoperation due to bleeding, symptoms that suggested neck hematoma and the consequences (both immediate and remote) of the bleeding itself.

\section{Statistical analysis}

For the statistical analysis, $p$-values were calculated by the $\chi^{2}$ test and Spearman's rank correlation test.

\section{Results}

Epidemiology and risk factors for bleeding among patients undergoing thyroid surgery

From 1996 to 2014, 7805 patients were operated on due to various pathologies of the thyroid gland at the Clinic of General, Gastroenterological and Endocrine Surgery (Tables I and II). Among them, $6884(88.2 \%)$ were female and 921 (11.8\%) were male. The mean age was $50 \pm 13$ years.

Bleeding occurred in 84 patients, i.e., $1.08 \%$ of all those who underwent thyroid surgery. Among 
Table II. Demographic and intraoperative characteristics of 7805 patients included in the study

\begin{tabular}{|c|c|c|c|c|}
\hline Demographic characteristics & $\begin{array}{c}\text { Number of all } \\
\text { patients } \\
N=7805(100 \%)\end{array}$ & $\begin{array}{l}\text { Number of } \\
\text { patients with } \\
\text { bleeding after } \\
\text { thyroidectomy } \\
N=84(100 \%)\end{array}$ & $\begin{array}{l}\text { Percentage of } \\
\text { all operated } \\
\text { patients } \\
(1.08 \%)\end{array}$ & $P$-value \\
\hline Age, mean \pm SD [years] & $50 \pm 13$ & $54 \pm 16$ & & \\
\hline Gender, $n(\%)$ : & & & & 0.006 \\
\hline Female & $6884(88.2)$ & $66(78.6)$ & $(1.0 \%)$ & \\
\hline Male & $921(11.8)$ & $18(21.4)$ & $(2.0 \%)$ & \\
\hline Thyroid pathology, primary operation, $n(\%)$ : & & & & 0.03 \\
\hline Nodular goiter & $5426(69.5)$ & $49(58.3)$ & (0.90\%) & \\
\hline Toxic nodular goiter & $934(12.0)$ & $15(17.9)$ & $(1.61 \%)$ & \\
\hline Graves-Basedow disease & $406(5.2)$ & $8(9.5)$ & $(1.97 \%)$ & \\
\hline Toxic adenoma & $125(1.6)$ & $4(4.8)$ & $(3.20 \%)$ & \\
\hline Thyroid cancer & $398(5.1)$ & $5(6.0)$ & $(1.26 \%)$ & \\
\hline Inflammatory goiter & $119(1.5)$ & $0(0.0)$ & $(0 \%)$ & \\
\hline Other (adenoid cell carcinoma, lymphoma) & $8(0.1)$ & $0(0.0)$ & $(0 \%)$ & \\
\hline $\begin{array}{l}\text { Secondary thyroid operations } \\
\text { (reoperation/recurrent goiter), } n(\%)\end{array}$ & $389(5.0)$ & $3(3.6)$ & $(0.77 \%)$ & 0.03 \\
\hline Retrosternal goiter, $n(\%)$ & $1626(20.8)$ & $24(28.6)$ & $(1.48 \%)$ & 0.08 \\
\hline Type of operation, $n$ (\%): & & & & $<0.001$ \\
\hline Lobectomy & $329(4.2)$ & $3(3.6)$ & (0.91\%) & \\
\hline Bilateral subtotal & $5684(72.8)$ & $47(56.0)$ & $(0.83 \%)$ & \\
\hline Dunhill procedure & $1086(13.9)$ & $13(15.5)$ & $(1.20 \%)$ & \\
\hline Total thyroidectomy & $618(7.9)$ & $19(22.6)$ & $(3.07 \%)$ & \\
\hline Other procedures (cytoreduction) & $88(1.1)$ & $2(2.4)$ & $(2.27 \%)$ & \\
\hline
\end{tabular}

the patients with bleeding, there were $66(78.6 \%)$ females and 18 (21.4\%) males. In relation to the overall number of patients operated on, there was a statistically significant difference in bleeding rates: $2.0 \%$ in males and $1.0 \%$ in females $(p=$ 0.006). The median age of the patients with bleeding was $54 \pm 16$ years; the youngest was 22 and the oldest 84 years old.

We observed a statistically significant increase in bleeding throughout the study period ( $p=$ 0.03). However, there is no significant correlation between the bleeding rates and time $(p=0.25)$ - Figure 1. More operations entail more bleeding, while the rate of bleeding remains relatively constant.

The amount of bleeding in relation to particular thyroid pathologies is shown in Table II. It can be seen that bleeding occurred most often in the group of patients operated on due to toxic goiter: toxic adenoma (3.20\%), Graves-Basedow disease (1.97\%) and toxic multinodular goiter (1.61\%).
Bleeding was less likely after operations due to thyroid cancer $(1.26 \%)$, multinodular goiter $(0.90 \%)$ and recurrent goiter $(0.77 \%)$. We observed no bleeding after operations for inflammatory goiter. There are statistically significant differences between the bleeding rates in the presented groups $(p=0.03)$. Goiter toxicity seems to be the greatest risk factor for postoperative bleeding.

Among the patients reoperated on because of bleeding, 24 (28.6\%) had retrosternal goiter. Comparing this to the overall number of patients with retrosternal goiter (1626), we concluded that is it not a statistically significant risk factor for bleeding $(p=0.08)$ - Table II.

Bleeding in relation to the scope of the operation is presented in Table II. Total resection of the thyroid gland was associated with the greatest risk of bleeding (3.07\%). The risk was also high $(2.27 \%)$ in palliative procedures (cytoreduction, tracheostomy, surgical biopsy of unresectable tumors). Lobectomy (0.91\%), bilateral subtotal 


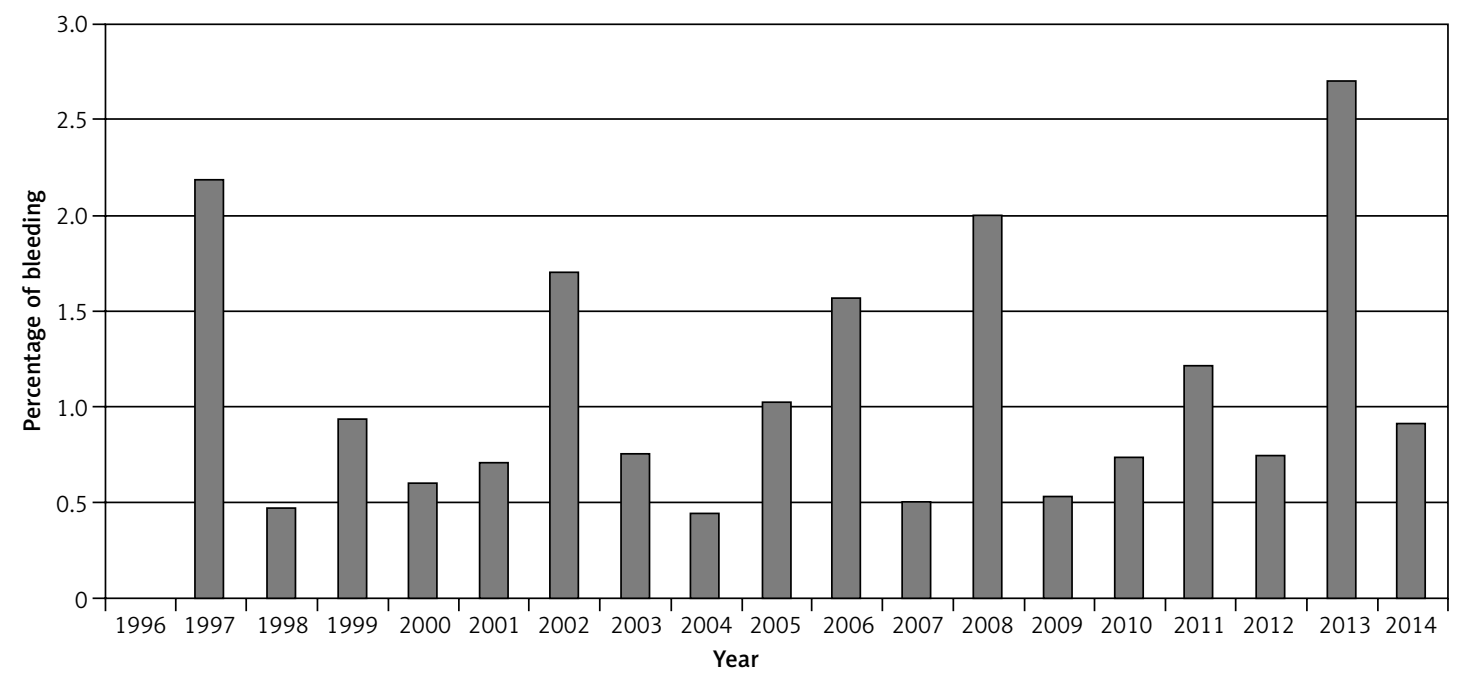

Figure 1. Amount of bleeding after thyroid operation in relation to all thyroid operations ( mean $=1.08 \%$ )

thyroidectomy $(0.83 \%)$ and Dunhill procedure $(1.20 \%)$ were less likely to cause bleeding. There is a strong $(p<0.001)$ statistical correlation between the scope of the operation and the risk of subsequent bleeding.

The surgeon's experience was not a significant risk factor for postoperative bleeding. It should be emphasized that all surgical residents at our clinic always perform thyroidectomies under the close supervision of an experienced surgeon.

\section{Consequences of bleeding after thyroid surgery}

The time from skin closure after primary surgery to reopening due to bleeding varied from $10 \mathrm{~min}$ to $24 \mathrm{~h}$. Most reoperations took place within $6 \mathrm{~h}$ after the primary procedure. One female patient, however, was reoperated on 22 days after thyroidectomy because of a large hematoma. Probably the first symptoms of bleeding developed about 7 days after surgery, but the patient came back to the surgical unit only when she felt severe pressure around her neck, accompanied by dyspnea.

\section{Symptoms of bleeding reported by patients}

In our study patients reported the following symptoms that suggested bleeding: increase of neck circumference: 41 (48.8\%), dyspnea: 46 (54.8\%), pressure on the neck: 73 (86.9\%), dysphagia: $5(5.9 \%)$, blood on the postoperative dressing: 30 (35.7\%), low blood pressure: 10 (11.9\%), volume of suction drain contents exceeding $150 \mathrm{ml}$ : $20(23.8 \%)$. In every patient with postoperative bleeding there was more than one symptom.

\section{Intervention due to diagnosed bleeding}

Eighty-three (98.8\%) bleeding patients were reoperated on in the surgical theater, and in 1 (1.2\%) case the intervention took place in the patient's bed due to acute respiratory distress. In 4 (4.8\%) patients there were significant difficulties with intubation; as a result in $1(1.2 \%)$ case a laryngeal mask airway was used, and 3 (3.6\%) patients with severe trachea compression needed their skin stitches released and the hematoma evacuated before successful intubation.

\section{Sources of bleeding}

In $88.8 \%$ of the cases of postoperative bleeding it was possible to identify the exact source; in the rest $(11.2 \%)$ the surgeon could not establish the origin of the bleeding. Table III presents all the sources. In 10 cases there were two sources, and in two cases there were three separate sources of bleeding.

Three (3.6\%) patients required a second reoperation due to recurrences of bleeding.

\section{Complications associated with bleeding and reoperation}

We observed complications associated with bleeding and reoperation in 24 (28.6\%) patients. Eight of them (9.5\%) required transfer to the intensive care unit (ICU) after reoperation. Significant blood loss occurred in 7 (8.33\%) patients, who needed blood transfusions ( 2 to 4 units of packed red blood cells).

The most severe complication was cardiac arrest, which we observed in 3 (3.57\%) patients. In one of them, cardiac arrest occurred as a result of acute respiratory failure before revision of the postoperative wound. She was successfully resuscitated, reoperated on and finally transferred to the ICU. In the second patient, cardiac arrest occurred just after wound revision; she was also successfully resuscitated and transferred to the ICU. 
The third one was an 80-year-old man who underwent palliative resection (cytoreduction) due to anaplastic thyroid cancer. In his case cardiac arrest occurred during wound revision due to severe bleeding that the surgeon was not able to control. The patient was diagnosed with disseminated intravascular coagulation (DIC) and unfortunately died during reoperation, despite intensive resuscitation and transfusion of more than four units of packed red blood cells.

One $(1.2 \%)$ female patient was diagnosed with cerebral stroke after revision, and another (1.2\%) with transient ischemic attack (TIA).

Severe bilateral vocal cord palsy was observed in $2(2.4 \%)$ female patients. The first one was primarily operated on due to a large retrosternal toxic goiter. Soon after the operation, postoperative hematoma with significant pressure on the trachea was diagnosed. As a result, there were significant problems with intubation and iatrogenic fractures of the laryngeal cartilages occurred. This initial diagnosis was confirmed by videofiberoscopic examination. The patient was then treated with glucocorticoid injections and vocal cord rehabilitation, and did not require tracheostomy. Six months after the laryngeal trauma she regained normal vocal cord motility.

Bilateral recurrent laryngeal nerve palsy also occurred in the previously mentioned 69-year-old patient who was admitted 22 days after a thyroidectomy with a postoperative hematoma. Immediately after her first surgery and before discharge from the hospital, an ENT specialist confirmed normal vocal cord function. After her second admission the patient was reoperated on and a large $(5 \mathrm{~cm} \times 6 \mathrm{~cm} \times 4 \mathrm{~cm})$ fibrotic hematoma was removed from the postoperative bed, but vocal cord motility did not return instantly. Nine months after reoperation, the patient regained function of a single vocal cord, while the other is permanently paralyzed.

Table III presents a list of the complications associated with bleeding and reoperation in the analyzed patients.

\section{Discussion}

Although the thyroid gland has both a rich vascular supply and high blood perfusion, bleeding after thyroidectomy occurs more often than after other surgical procedures. The surgeon should always provide adequate hemostasis before skin closure, whether possible risk factors for bleeding are present or not. We agree with Morton et al. [13] that a postoperative Valsalva maneuver is a good, commonly used practice for evaluating hemostasis before wound closure. There are surgical centers that perform a Trendelenburg tilt as well [14], but this has never been done in our clin-
Table III. Origins of bleeding and complications associated with bleeding and reoperation

\begin{tabular}{|c|c|}
\hline Bleeding after thyroid surgery & $N=84(100 \%)$ \\
\hline \multicolumn{2}{|c|}{ Origin of bleeding identified during reoperations: } \\
\hline Skin and subcutaneous tissue & $18(18)$ \\
\hline $\begin{array}{l}\text { Neck muscle/strap muscles } \\
\text { and sternocleidomastoid muscle }\end{array}$ & $18(18)$ \\
\hline Thyroid stump & $18(18)$ \\
\hline Trachea & $11(13.1)$ \\
\hline Branches of thyroid arteries & $11(13.1)$ \\
\hline Thyroid pole & $7(8.3)$ \\
\hline Thyroid bed & $4(4.7)$ \\
\hline Not identified or many origins & $11(13.1)$ \\
\hline \multicolumn{2}{|c|}{$\begin{array}{l}\text { Complications associated with bleeding } \\
\text { and reoperation: }\end{array}$} \\
\hline Cardiac arrest & $3(3.57)$ \\
\hline Cerebral stroke & 1 (1.19) \\
\hline TIA & $1(1.19)$ \\
\hline Bilateral vocal cord palsy & $2(2.38)$ \\
\hline Unilateral vocal cord palsy & $3(3.57)$ \\
\hline Parathyroid insufficiency & $28(33.33)$ \\
\hline Death & $1(1.19)$ \\
\hline
\end{tabular}

ic. There is no universal consensus on using drains after thyroidectomy. In our clinic they are routinely used after every thyroid operation, but there is no clinical study that statistically proves drainage beneficial, as shown in the meta-analysis carried out by Kennedy et al. [15]. In addition, the authors of that study pointed out that there is no scientific basis for recommending routine drainage after thyroidectomy, and it is even possible that the presence of a drain increases the rate of postoperative bleeding [15]. In our experience drainage often allows bleeding to be diagnosed sooner, thus hastening reoperation and decreasing the likelihood of other postoperative complications.

Knowledge of the risk factors and potential consequences of bleeding for a patients' quality of life is essential in thyroid surgery. Some studies have analyzed many risk factors but found that none of them has a statistically significant influence $[1-4,7,16]$. In our analysis, the patient's sex, preoperative diagnosis and the scope of the operation were found to be significant risk factors. Bleeding occurs more often in males (2\% vs. $1 \%$; $p=0.006)$, as in a study by Caló et al. [17]. Bleeding is much more frequent after total resections than after partial ones $(p<0.001)[9,10,18]$. The type of preoperative thyroid pathology also influ- 
ences the rate of bleeding [10]; the risk is highest in toxic goiter $(p=0.03)$. Most of the hemostatic abnormalities associated with thyroid dysfunction are the consequences of direct effects of thyroid hormones on the synthesis of various hemostatic factors. Moreover, thyroid autoimmunity may also modify the processes of primary and secondary hemostasis. Hyperthyroidism is generally associated with hypercoagulability and hypofibrinolysis. However, further, larger studies are required. Retrosternal goiter $(p=0.08)$ and the surgeon's experience are not significant risk factors for bleeding.

Other authors have indicated age as a significant risk factor [19], and have also looked for other, less specific factors with potential prognostic value. Morton et al. [13] identified elevated systolic blood pressure (over $150 \mathrm{~mm} \mathrm{Hg}$ ) as such a factor. The negative effects of hypertension in the postoperative period are also emphasized by Caló et al. [17]. Basto et al. observed that bleeding occurs less often when patients receive ketoprofen after surgery [20]. Proper postoperative care - maintaining optimal blood pressure, appropriate analgesia, prevention of postoperative nausea and vomiting (PONV), managing coexisting chronic conditions - are as important for a good outcome as the procedure itself $[21,22]$. In a study by Bononi et al., bleeding was related to PONV [23].

It is important to regard bleeding itself as a risk factor for subsequent complications. In our material about half of the patients that had postoperative bleeding suffered another complication (e.g., cardiac arrest or stroke) and 9.5\% of them required transfer to the ICU after revision. Mortality due to bleeding and reoperation in our study group was $1.19 \%$ (one death out of 84 patients with bleeding), which was higher than in the study by Promberger et al. (3 deaths out of 519 patients with bleeding $=0.58 \%$ ) [9]. Two $(2.4 \%)$ patients in our study suffered bilateral vocal cord palsy. Fortunately, neither of them required tracheostomy, while other authors described such a necessity in $1.7 \%$ of cases [9]. However, there was another severe iatrogenic complication in our material, namely fracture of the laryngeal cartilages during a difficult intubation (1 patient). The use of neuromonitoring allowed us to distinguish this mechanical laryngeal trauma from intraoperative damage to the recurrent laryngeal nerve.

Most authors confirm the importance of careful monitoring during the first $6 \mathrm{~h}$ after thyroid surgery [19]. Special attention should be paid to such alarming symptoms as dyspnea, neck edema, a feeling of pressure and an unusual amount of blood in the suction drain. Thus monitoring for at least $24 \mathrm{~h}$ after a thyroidectomy seems justified. The case of our patient who was taking anticoagulants and developed a neck hematoma 7 days after surgery suggests that high risk pa- tients should be instructed to observe their necks even after discharge from the hospital. A female patient, suffering from type 2 diabetes and arterial hypertension, was undergoing anticoagulant treatment (acenocoumarol $4 \mathrm{mg}$ p.o. once a day) due to permanent atrial fibrillation. International normalized ratio (INR) values were within the therapeutic range. Five days before thyroidectomy acenocoumarol was discontinued and fractionated heparin (nadroparin $0.6 \mathrm{ml}$ s.c. once a day) was applied instead. After a successful operation, on the second postoperative day we switched back to acenocoumarol, monitored by INR values. We admit that such management could have increased this patient's risk for postoperative bleeding and neck hematoma. In such patients adequate treatment of coexisting chronic conditions is of great importance.

Bleeding after thyroid surgery is still significant and is often associated with severe complications $[24,25]$. Diagnosed in time, it can be managed with a good outcome, while delayed intervention may cause subsequent life-threatening complications [17].

In conclusion, bleeding after thyroidectomy is a direct life threat that requires immediate intervention. As a result of bleeding, death may occur (1.19\%); about half of the patients suffer other complications; and $9.5 \%$ of them require intensive care. Male sex, toxic goiter and total thyroidectomy are statistically significant risk factors for postoperative bleeding, while retrosternal goiter and the surgeon's experience are not. Every patient after thyroid surgery needs to be closely observed by experienced doctors and nurses. Immediate intervention in the operating theater and access to the ICU should be available at all times.

\section{Conflict of interest}

The authors declare no conflict of interest.

\section{References}

1. Ozbas S, Kocak S, Aydintug S, Cakmak A, Demirkiran MA, Wishart GC. Comparison of the complications of subtotal, near total and total thyroidectomy in the surgical management of multinodular goiter. Endocr J 2005; 52: 199-205.

2. Zambudio AR, Rodriguez J, Riguelme J, Soria T, Canteras $M$, Parrilla $P$. Prospective study of postoperative complications after total thyroidectomy for multinodular goiters by surgeons with experience in endocrine surgery. Ann Surg 2004; 240: 18-25.

3. Thomusch O, Machens A, Sekulla C, et al. Multivariate analysis of risk factors for postoperative complications in benign goiter surgery: prospective multicenter study in Germany. World J Surg 2000; 24: 1335-41.

4. Friguglietti CU, Lin CS, Kulcsar MA. Total thyroidectomy for benign thyroid disease. Laryngoscope 2003; 113: 1820-6. 
5. Bhattacharyya N, Fried MP. Assessment of the morbidity and complications of total thyroidectomy. Arch Otolaryngol Head Neck Surg 2002; 128: 389-92.

6. Abbas G, Dubner S, Heller KS. Re-operation for bleeding after thyroidectomy and parathyroidectomy. Head Neck 2001; 23: 544-6.

7. Rosato L, Avenia N, Bernante P, et al. Complications of thyroid surgery: analysis of a multicentric study on 14934 patients operated on in Italy over 5 years. World J Surg 2004; 28: 271-6.

8. Bergenfelz A, Jansson S, Kristoffersson A, et al. Complications to thyroid surgery: results as reported in a database from a multicenter audit comprising $3.660 \mathrm{pa}-$ tients. Langenbecks Arch Surg 2008; 393: 667-73.

9. Promberger R, Ott J, Kober F, et al. Risk factors for postoperative bleeding after thyroid surgery. Br I Surg 2012; 99: 373-9.

10. Godballe C, Madsen AR, Pedersen HB, et al. Post-thyroidectomy hemorrhage: a national study of patients treated at the Danish Departments of ENT Head and Neck Surgery. Eur Arch Othorhinolaryngol 2009; 266: 1945-52.

11. Reeve T, Thompson NW. Complications of thyroid surgery: how to avoid them, how to manage them, and observations on their possible effect on the whole patient. World J Surg 2000; 24: 971-5.

12. Rosenbaum MA, Haridas M, McHenry CR. Life-threatening neck hematoma complicating thyroid and parathyroid surgery. Am I Surg 2008; 195: 339-43.

13. Morton R, Mak V, Moss D, Ahmad Z, Sevao J. Risk of bleeding after thyroid surgery: matched pairs analysis. J Laryngol Otol 2012; 126: 285-8.

14. Moumoulidis I, Martinez Del Pero M, Brennan L, Jani P. Haemostasis in head and neck surgical procedures: Valsalva manoeuvre versus Trendelenburg tilt. Ann R Coll Surg Engl 2010; 92: 292-4.

15. Kennedy SA, Irvine RA, Westerberg BD, Zhang H. Meta-analysis: prophylactic drainage and bleeding complications in thyroid surgery. J Otolaryngol Head Neck Surg 2008; 37: 768-73.

16. Burkey SH, van Heerden JA, Thompson GB, Grant CS, Schleck CD, Farley DR. Reexploration for symptomatic hematomas after cervical exploration. Surgery 2001; 130: 914-20.

17. Caló PG, Pisano G, Piga G, et al. Postoperative hematomas after thyroid surgery. Incidence and risk factors in our experience. Ann Ital Chir 2010; 81: 343-7.

18. Hermann M, Alk G, Roka R, Glasser K, Freissmuth M. Laryngeal recurrent nerve injury in surgery for benign thyroid diseases: effect of nerve dissection and impact of individual surgeon in more than 27000 nerves at risk. Ann Surg 2002; 235: 261-8.

19. Prim MP, De Diego J, Harisson D, et al. Factors related to nerve injury and hypocalcemia in thyroid gland surgery. Otolaryngol Head Neck Surg 2001; 124: 111-4.

20. Basto ER, Waintrop C, Mourey FD, Landru JP, Eurin BG, Jacob LP. Intravenous ketoprofen in thyroid and parathyroid surgery. Anesth Analg 2001; 92: 1052-7.

21. Harding J, Sebag F, Sierra M, Palazzo FF, Henry JF. Thyroid surgery: postoperative hematoma prevention and treatment. Langenbecks Arch Surg 2006; 391: 169-73.

22. Sibel E, Cicero AF. Hyperthyroidism and cardiovascular complications: a narrative review on the basis of patophysiology. Arch Med Sci 2013; 9: 944-52.

23. Bononi M, Amore Bonapasta SA, Vari A, et al. Incidence and circumstances of cervical hematoma complicating thyroidectomy and its relationship to postoperative vomiting. Head Neck 2010; 32: 1173-7.
24. Majid MA, Siddique MI. Major post-operative complications of thyroid surgery: preventable or not? Bangladesh Med Res Counc Bull 2008; 34: 99-103.

25. Joannis V, Aliki T, Nikolaos A, Fotios N, Petroipoulos T, Smyrniotis V. Total thyroidectomy as the single surgical option for benign and malignant thyroid disease: a surgical challenge. Arch Med Sci 2013; 9: 74-8. 